\title{
Acute Megakaryoblastic Leukemia in Children: Diagnosis and Manag- ement Challenges in Resource-Poor Countries
}

\author{
S. Cherkaoui ${ }^{*}$ M. Bendari, A. Madani, A. Quessar and S. Benchekroun
}

Department of Hematology and Pediatric Oncology, hospital 20 Août1953, Ibn Rochd University hospital, Casablanca, Morocco

\begin{abstract}
Acute Megakaryoblastic Leukemia (AMKL) is a rare subtype of acute myeloid leukemia classified as AML M7 by the French-American-British (FAB) Leukemia Cooperative Study Group. We reviewed the records of children aged less than 18 years with AMKL during the period from January 2003 to December 2010. The diagnosis of AMKL was established on the basis of the FAB criteria and confirmed by immunophenotyping. Eight cases were assigned for this period. The incidence rate of AMKL was $5.5 \%$ of AML. The median age at the time of diagnosis was 1 year. The karyotype presented translocation $(1,22)$ in two cases. One girl had Down syndrome (DS). Treatment included two inductions based on daunorubicin and cytosine arabinoside $(7+3)$ followed by two consolidations with high dose of cytosine arabinoside $\left(16 \mathrm{~g} / \mathrm{m}^{2}\right)$. Complete remission (CR) was achieved in 3 patients $(43 \%)$. One patient underwent allogeneic stem cell transplant (SCT) and is still enjoying continuous CR 5 years after treatment. Other patients died from failure or relapse. In this small series from a single institution, reported incidence of AMKL is underestimated probably due to the difficulties of diagnosis. The prognosis was poor, particularly because of unavailability of intensified chemotherapy treatment and allogeneic SCT.
\end{abstract}

Keywords: Acute Megakaryoblastic Leukemia, children, treatment.

\section{INTRODUCTION}

Acute Megakaryoblastic Leukemia (AMKL) has been classified as the seventh subtype of Acute Myeloid Leukemia AML (M7) by the French-American-British (FAB) Leukemia Cooperative Study Group [1]. AMKL has been identified as a separate entity for long time [2]. Although initially thought to be rare among children, AMKL has been diagnosed with increasing frequency in this age group [3]. It is the commonest form of AML in children with Down Syndrome (DS) [4, 5]. Most of the evidences regarding this entity originate from developed countries [3, 6-8], there is one case report from India [9]. Thus, we decided to evaluate our experience in diagnosis, management and outcome of children with AMKL.

\section{PATIENTS AND METHODS}

\section{Patients and Diagnostic of AMKL}

All children diagnosed with AMKL in the Department of Hematology and Pediatric Oncology, 20 Août1953 Hospital in Casablanca, from January 2003 to December 2010 were included in the study.

Details of clinical presentation, laboratory findings at the time of diagnosis, therapy received, and outcome were collected from the case files and AML database.

*Address correspondence to this author at the Department of Hematology and Pediatric Oncology, hospital 20 Août1953, Ibn Rochd University hospital, Casablanca, Morocco, 26, rue de bruxelles appartement 27, casablanca, Morocco; Tel: +212 6 61300048; E-mail: sihamc@gmail.com
Acute leukemia was diagnosed by the presence of at least $20 \%$ blasts in the bone marrow. The diagnosis of AMKL was established on the basis of the FAB criteria by studies of cell morphology and cytochemistry [1] and was confirmed by immunophenotyping [10].

Cytogenetic studies were performed on bone marrow samples taken at the time of diagnosis and analyzed by standard methods.

\section{Treatment}

All children were included according to national AML protocol used since April 2003 (AML-MA 2003) which consists of a pre-phase based on Hydroxyurea at 50 $\mathrm{mg} / \mathrm{Kg} / \mathrm{day}$ during 4 days if $\mathrm{WBC} \geq 50.000 \mathrm{G} / \mathrm{L}$, two inductions courses (Daunorubicin at $50 \mathrm{mg} / \mathrm{m}^{2} /$ day x 3 days and cytosine arabinoside at $200 \mathrm{mg} / \mathrm{m}^{2} /$ day $\mathrm{x} 7$ days) with intrathecal therapy followed by two consolidations with $2 \mathrm{~g} /$ $\mathrm{m}^{2}$ of cytosine arabinoside twice a day during 4 days with Asparaginase at $6000 \mathrm{IU} / \mathrm{m}^{2}$.

\section{RESULTS}

During the study period, 145 patients under 18 years were diagnosed with AML and eight patients with AMKL. The incidence rate of AMKL was therefore $5.5 \%$ of AML.

The median age at the time of diagnosis of AMKL was 1 year (range: 6 month 2 years). The M:F ratio was $2: 6$. The average time for consultation was 2 months (range: 2 weeks1 year). The diagnosis was made based on the signs of medullar insufficiency in all cases. Presenting findings 
Table 1. Clinical, hematological and one marrow findings at the time of diagnosis.

\begin{tabular}{|c|c|c|c|c|c|c|c|c|}
\hline & Case 1 & Case 2 & Case 3 & Case 4 & Case 5 & Case 6 & Case 7 & Case 8 \\
\hline Age (months) & 18 & 9 & 24 & 12 & 6 & 6 & 8 & 20 \\
\hline Sex & $\mathrm{F}$ & F & M & M & $\mathrm{F}$ & $\mathrm{F}$ & F & $\mathrm{F}$ \\
\hline Anemic syndrome & + & + & - & - & + & + & + & + \\
\hline Infectious syndrome & - & + & + & + & + & + & + & + \\
\hline Hemorrhagic syndrome & + & + & + & + & - & - & + & + \\
\hline Splenomegaly & + & + & - & - & - & + & - & + \\
\hline Hepatomegaly & - & + & - & - & - & - & - & - \\
\hline Lymph nodes & - & + & - & - & - & + & - & + \\
\hline Down's syndrome & + & - & - & - & - & - & - & - \\
\hline $\mathrm{Hb}(\mathrm{g} / \mathrm{dl})$ & 5 & 6 & 12 & 13 & 8 & 11 & 4 & 3 \\
\hline $\operatorname{WBC}\left(\times 10^{9} / \mathrm{l}\right)$ & 135 & 33 & 7 & 24 & 17 & 4 & 31 & 139 \\
\hline Circulating blats (\%) & 84 & 80 & 34 & 60 & 40 & 0 & 31 & 90 \\
\hline Platelets (x $\left.10^{9} \mathrm{G} / \mathrm{l}\right)$ & 71 & 74 & 28 & 15 & 19 & 21 & 26 & 13 \\
\hline BM cellularity & +++ & ++ & ++++ & +++ & ++++ & + & $++/-$ & ++++ \\
\hline BM \% blasts & 96 & & 45 & 75 & 94 & 65 & 94 & 90 \\
\hline Cytochemistry (MPO) & - & - & - & - & - & - & - & - \\
\hline Cytogenetic study & Trisomy 21 & $\begin{array}{c}\mathrm{T}(1,22) \\
-8,-19\end{array}$ & $\begin{array}{c}49 \mathrm{XY} \\
+2,+8,+22\end{array}$ & ND & Trisomy 22 & $\mathrm{~T}(1,22)$ & normal & $\mathrm{T}(16,18)$ \\
\hline
\end{tabular}

included bone pain in 1 patient and bilateral exophthalmos in 1 patient. One female had Down syndrome. Radiological exams found diffuse bone lysis in 1 case.

Table 1 summarizes clinical, hematological and bone marrow features at the time of diagnosis.

In all cases, bone marrow aspirate confirmed the diagnosis of AML M7 and leukemic cells expressed at least one platelet-associated antigen (CD36, CD41a, or CD 61). The karyotype objectified translocation $(1,22)$ in two cases (Table 1).

Parents refused treatment in one case. 7 patients received induction course. The patient with Down syndrome died at day 15 of chemotherapy from hemorrhagic syndrome despite platelet transfusion, she had thrombocytopenia at $3000 / \mathrm{mm}^{3}$. Three patients did not achieve complete remission (CR) after first cycle of chemotherapy and died in disease progression. All 3 remaining patients achieved CR (43\%). One patient (case 3) underwent allogeneic stem cell transplant (SCT) in another country with genoidentic donor and is still enjoying continuous CR 5 years after SCT; whereas other two patients died from relapse after 9 months and 3 years respectively and half died on completion of therapy.

Of whole AML cohort, $70 \%$ of patients achieved CR after induction courses. Among them, 27\% attained CR and $36 \%$ experienced hematological relapse.

\section{DISCUSSION}

In this small series from a single institution in Morocco, $5.5 \%$ of children with AML were identified as AMKL. The incidence of AMKL varies between 7.1 and $19.1 \%$ of AML cases in children [3, 6-8]. Recently, Hama et al. have reported much higher incidence of AMKL at 23.2\% in Japan [11]. This may indicate that the reported incidence of AMKL in our series may be an underestimation probably due to the difficulties of diagnosis.

The median age at diagnosis was 1 year, which was lower than that in the total group of children with AML (13 years) and also lower than what is reported in literature $[6,8$, 11].

With the available combination of morphologic, cytochemical, cytogenetic, and immunophenotypic methods, AMKL can be reliably diagnosed [12]. In all children, the expression of at least one megakaryoblastic antigen could be shown.

Acute megakaryoblastic leukemia is the most frequent type of AML in children with DS, and its prognosis is excellent in this group of patients with less intensive chemotherapy $[4,5,11]$. The remission rate is approximately $96 \%$ with overall and event-free survival (EFS) of 79\% [11]. Unfortunately, death of the female with DS was due to the treatment toxicity. On the other hand, in children with 
Table 2. Bone marrow features.

\begin{tabular}{|c|c|c|c|c|c|c|c|c|}
\hline & Case 1 & Case 2 & Case 3 & Case 4 & Case 5 & Case 6 & Case 7 & Case 8 \\
\hline \multicolumn{9}{|l|}{ BM Morphology } \\
\hline Cellularity & +++ & ++ & ++++ & +++ & ++++ & + & $++/-$ & ++++ \\
\hline$\%$ blasts & 96 & & 45 & 75 & 94 & 65 & 94 & 90 \\
\hline \multicolumn{9}{|l|}{ Cytochemistry } \\
\hline MPO & - & - & - & - & - & - & - & - \\
\hline \multicolumn{9}{|l|}{ Immunophenotype } \\
\hline CD41a (\%) & 88 & + & 81 & + & 88 & 90 & + & 40 \\
\hline CD61 (\%) & 87 & + & 85 & + & 82 & 84 & + & 86 \\
\hline CD36 (\%) & 94 & + & ND & ND & ND & ND & ND & 2 \\
\hline Cytogenetics study & Trisomy 21 & $\begin{array}{l}\mathrm{t}(1,22) \\
-8,-19\end{array}$ & $\begin{array}{c}49 \mathrm{XY} \\
+2,+8,+22\end{array}$ & ND & Trisomy 22 & $\mathrm{t}(1,22)$ & normal & $\mathrm{t}(16,18)$ \\
\hline
\end{tabular}

non-DS, AMKL appeared to be more heterogeneous and showed close association with $\mathrm{t}(1 ; 22)(\mathrm{p} 13 ; \mathrm{q} 13)[6,8,11$, 13].

The outcome of children with non-DS was poor in previous report with 2 year overall survival (OS) in only $14 \%$ [6], but a recent study showed improvement of OS and EFS at 76 and $57 \%$ respectively [11]. Reinhardt et al. reported a significant improvement in the $\mathrm{CR}$ rate and in EFS in AMKL patients from early AML-BFM 87 trial $(58 \% /$ $11 \%)$ to AML-BFM 93 (77\%/ 41\%) and AML-BFM98 $(84 \% / 41 \%)$ after intensified induction treatment [8]. In this trial, AMKL was not identified with especially poor prognosis. While increased treatment intensity has improved outcomes for children with acute megakaryoblastic leukemia (AMKL), the prognostic and therapeutic implications of megakaryoblastic differentiation remain controversial with some groups treating such disease as high risk and recommending hematopoietic stem cell transplantation (HSCT) during first remission, while others treating it as standard risk in the absence of unfavorable cytogenetics and/or a poor response to induction therapy [14].

In this study, we report a poor outcome with $\mathrm{CR}$ rate at $43 \%$ and only one survivor at 5 year $(14 \%)$. However, in patients with AMKL compared the total group of children with high risk AML $(n=50)$ treated in AML-MA study, the $\mathrm{CR}$ rate was comparable at $47 \%$ and the 5-year OS was at $17 \%$.

In conclusion, we have characterized the clinical and biologic features and outcome of a small series of pediatric patients with AMKL. Treatment included standard chemotherapy and prognosis was poor. This finding supports the new Moroccan AML design based on intensification of therapy with improvement in supportive care.

\section{CONFLICT OF INTEREST}

The authors confirm that this article content has no conflict of interest.

\section{ACKNOWLEDGEMENTS}

We thank Dr Uma Athale for her critical review of this manuscript.

\section{REFERENCES}

[1] Bennett JM, Catovsky D, Daniel MT, et al. Criteria for the diagnosis of acute leukemia of megakaryocyte lineage (M7): a report of the French-American-British Cooperative Group. Ann Intern Med 1985; 103: 460-2.

[2] Jaffe S, Harris LN, Stein H, Vardiman WJ, Eds. "Acute myeloid leukemia," In: WHO Classification of Tumors. Lyon, France: IARC, 2001; pp. 99-102.

[3] Ribeiro RC, Oliveira MS, Fairclough D, et al. Acute megakaryoblastic leukemia in children and adolescents: a retrospective analysis of 24 cases. Leuk Lymphoma 1993; 10: 299306.

[4] Ravindranath Y, Abella E, Krischer JP, et al. Acute myeloid leukemia (AML) in Down's syndrome is highly responsive to chemotherapy: experience on Pediatric Oncology Group AML Study 8498. Blood 1992; 80: 2210-4.

[5] Lange BJ, Kobrinsky N, Barnard DR, et al. Distinctive demography, biology, and outcome of acute myeloid leukemia and myelodysplastic syndrome in children with Down syndrome: children's cancer group studies 2861 and 2891. Blood 1998; 91: 608-15.

[6] Athale UH, Razzouk BI, Raimondi SC, et al. Biology and outcome of childhood acute megakaryoblastic leukemia: a single institution's experience. Blood 2001; 97: 3727-32.

[7] Paredes-Aguilera R, Romero-Guzman L, Lopez-Santiago N, Trejo RA. Biology, clinical, and hematologic features of acute megakaryoblastic leukemia in children. Am J Hematol 2003; 73: 71-80.

[8] Reinhardt D, Diekamp S, Langebrake C, et al. Acute megakaryoblastic leukemia in children and adolescents, excluding Down's syndrome: improved outcome with intensified induction treatment. Leukemia 2005; 19: 1495-6.

[9] Sharma S, Nangia A, Jain MS et al. Clinico-Haematological profile of acute megakaryoblastic leukaemia: report of five cases. Adv Hematol 2009: 461912.

[10] San MJF, Gonzalez M, Cañizo MC et al. Leukemias with megakaryoblastic involvement: clinical, hematologic, and immunologic characteristics. Blood 1988; 72: 402-7.

[11] Hama A, Yagasaki H, Takahashi Y. Acute megakaryoblastic leukemia (AMKL) in children: a comparison of AMKL with and without Down syndrome. Brit J Hematol 2008; 140: 552-61. 
[12] Behm FG. Diagnosis of childhood acute myeloid leukemia. Clin Lab Med 1999; 19: 187-237.

[13] Bernstein J, Dastugue N, Haas OA et al. Nineteen cases of the t (1; 22)(p13; q13) acute megakaryblastic leukaemia of infants/children and a review of 39 cases: report from a $t(1 ; 22)$ study group. Leukemia 2000; 14 : 216-8.
[14]

O'Brien MM, Cao X, Pounds S, et al. Prognostic features in acute megakaryoblastic leukemia in children without Down syndrome: a report from the AML02 multicenter trial and the Children's Oncology Group Study POG 9421. Leukemia 2013; 27: 731-4.

Received: January 06, 2014

Revised: April 21, 2014

Accepted: May 02, 2014

(C) Cherkaoui et al.; Licensee Bentham Open.

This is an open access article licensed under the terms of the Creative Commons Attribution Non-Commercial License (http://creativecommons.org/licenses/by$\mathrm{nc} / 3.0 /$ ), which permits unrestricted, non-commercial use, distribution and reproduction in any medium, provided the work is properly cited. 